\title{
Variants in KITLG predispose to testicular germ cell cancer independently from spermatogenic function
}

\author{
Alberto Ferlin, Manuel Pengo, Damiano Pizzol, Umberto Carraro, \\ Anna Chiara Frigo ${ }^{1}$ and Carlo Foresta
}

Section of Clinical Pathology and Centre for Human Reproduction Pathology, Department of Histology, Microbiology and Medical Biotechnologies, University of Padova, Via Gabelli 63, 35121 Padova, Italy

${ }^{1}$ Department of Environmental Medicine and Public Health, University of Padova, 35100 Padova, Italy

(Correspondence should be addressed to A Ferlin; Email: alberto.ferlin@unipd.it)

\begin{abstract}
Epidemiological data suggest an association and a common pathogenetic link between male infertility and testicular germ cell tumor (TGCT) development. Genome-wide studies identified that TGCT susceptibility is associated with KITLG (c-KIT ligand), which regulates the formation of primordial germ cells, from which TGCT is believed to arise and spermatogenesis develops. In this study, we analyzed the link between KITLG, TGCT, and spermatogenic disruption by performing an association study between the KITLG markers rs995030 and rs4471514 and 426 TGCT cases and 614 controls with normal and abnormal sperm count. We found that TGCT risk was increased more than twofold per copy of the major G allele and A allele in KITLG rs995030 and rs 4471514 (odds ratio $(\mathrm{OR})=2.38,95 \%$ confidence interval $(95 \% \mathrm{Cl})=1.81-3.12 ; \mathrm{OR}=2.43,95 \% \mathrm{Cl}=$ 1.86-3.17 respectively), and homozygotes for the risk allele had a sevenfold increased risk of TGCT. KITLG markers were strongly associated with seminoma subtype (per allele risk increased more than threefold, homozygote risk increased by 13- to 16-fold) and weakly with nonseminoma. KITLG markers were not associated with sperm production, as no difference was observed in men with normozoospermia and azoo-oligozoospermia, both in controls and in TGCT cases. In conclusion, this study provides evidence that KITLG variants are involved in TGCT development and they represent an independent and strong specific risk factor for TGCT independently from spermatogenic function. A shared genetic cause and a common pathogenetic link between TGCT development and impairment of spermatogenesis are not evident from this study.
\end{abstract}

Endocrine-Related Cancer (2012) 19 101-108

\section{Introduction}

Testicular cancer (TC) is the most common cancer in males aged $20-40$ years, with a worldwide incidence of 7.5 per 100000 , but the rates vary considerably between countries and ethnic groups (Horwich et al. 2006). About $95 \%$ of all TCs are represented by testicular germ cell tumors (TGCTs), which include seminoma and nonseminoma histological types.

Although environmental factors clearly contribute to TGCT development, the genetic component is also strong and the proportion of TGCT susceptibility accounted for by the genetic effects is estimated at $25 \%$ (Czene et al. 2002). TGCT has high familial risks compared with most other cancer types that are generally no more than twofold (Dong \& Hemminki
2001): brothers of individuals with TGCT have an 8- to 12-fold increased risk of disease, and sons of affected individuals have a four- to six-fold increased risk (Swerdlow et al. 1997, Hemminki \& Li 2004). Despite this strong familial relative risk, early results from linkage studies identified a limited relationship with genetic factors (Crockford et al. 2006), suggesting that TGCT is a genetically complex trait.

The $\mathrm{gr} / \mathrm{gr}$ deletion on the $\mathrm{Y}$ chromosome, which seems to increase TGCT risk twofold to threefold and is also associated with spermatogenic impairment (Ferlin et al. 2005, Stouffs et al. 2011), might account only for a limited number of cases because carrier frequency of this variant is low (2-3\%; Nathanson et al. 2005). More recently, four genome-wide 
association studies (GWAS) from UK and USA have reported association of TGCTs with six new loci (KITLG, SPRY4, BAK1, DMRT1, TERT, and ATF7IP; Kanetsky et al. 2009, 2011, Rapley et al. 2009, Turnbull et al. 2010). The strongest association for TGCT susceptibility was found for SNPs in KITLG (ligand for the membrane-bound receptor tyrosine kinase KIT) gene with a $>2.5$-fold increased risk of disease per major allele (Kanetsky et al. 2009, Rapley et al. 2009), which is the highest reported for any cancer to date (Chanock 2009). The KITLG-KIT system regulates the survival, proliferation, and migration of primordial germ cells (PGCs; Runyan et al. 2006, Boldajipour \& Raz 2007), the cells from which spermatogonia and spermatocytes develop and from which TGCT is believed to arise. Accordingly, altered differentiation of PGCs is associated with the development of TGCT and infertility in mice (Heaney et al. 2008) and probably also in humans (Galan et al. 2006, Rajpert-De Meyts \& Hoei-Hansen 2007).

The relationship between different aspects of PGC development, TGCT susceptibility, and spermatogenic disruption, and the well-known epidemiological data suggesting an association and a common pathogenetic link between male infertility and TGCT development (Skakkebaek et al. 2001, Horwich et al. 2006, Rajpert-De Meyts 2006), led us to perform the current association study to clarify the possible link between KITLG, TGCT, and spermatogenic disruption. In fact, analysis of KITLG variation in TGCT men with a history of infertility, even if suggested, was not tested in GWAS (Kanetsky et al. 2009, Rapley et al. 2009). We therefore analyzed the association between previously identified SNPs in KITLG (Kanetsky et al. 2009, Rapley et al. 2009) and TGCT cases and controls with normal and disrupted spermatogenesis.

\section{Materials and methods}

\section{Cases and controls}

TGCT cases $(n=426)$ were recruited over the last 10 years among patients referred to our center for semen analysis. As a standard procedure, semen analysis is performed in every TGCT case just after TGCT diagnosis, before orchiectomy. To avoid confounding factors, selected TGCT cases had no history of cryptorchidism and familial history of TGCT and were affected by classic seminoma $(n=251)$ or nonseminoma (including yolk sac, choriocarcinoma, and embryonal carcinoma; $n=175$ ), excluding mixed phenotypes. Extragonadal TGCTs were also excluded and all TGCT cases were unrelated.
Controls $(n=614)$ were recruited among men referred to our center for standard semen analysis, and TC was excluded by andrological examination and testicular ultrasound. Standard semen analysis was performed in cases and controls according to World Health Organization protocol and subjects were considered as having a normal spermatogenesis when total sperm count was $\geq 40$ million/ejaculate (World Health Organization 1999). Oligozoospermic subjects (sperm count $<40$ million/ejaculate) were further analyzed to exclude possible causes of spermatogenic impairment (seminal infection, sperm autoantibodies, varicocele, history of cryptorchidism and orchitis, Y chromosome microdeletions (Ferlin et al. 2007), karyotype anomalies, medication, fever in the previous month, systemic diseases, and endocrine disorders), so that oligozoospermia might be considered idiopathic. All cases and controls were from the northeast of Italy.

The study has been approved by the Local Institutional Review Board, and informed consent was obtained from each subject after full explanation of the purpose and nature of all the procedures used. The study has been conducted in accordance with the principles expressed in the Declaration of Helsinki.

\section{KITLG variant analysis}

KITLG polymorphisms were analyzed by direct sequencing (ABI PRISM 3730XL DNA Sequencer, Applied Biosystems, Monza, Italy). Genomic DNA was extracted from peripheral blood leukocytes using QIAamp DNA Blood Midi Kit according to the manufacturer's protocol (Qiagen). The oligonucleotide primers used for the analysis were the following: $5^{\prime}$-GCAAATTTGTTACTCATTCTGTGG-3' and $5^{\prime}$ CAGTACTGGCTCCCTTGCAT-3' for rs995030; $5^{\prime}$-TGGGGAGGCAGAGGATAAAT- $3^{\prime}$ and $5^{\prime}$ TCATTGACATGCCTGAGACAC- $3^{\prime}$ for rs 4474514.

Table 1 Characteristics of testicular germ cell tumor cases and controls

\begin{tabular}{|c|c|c|c|c|}
\hline \multirow[b]{2}{*}{ Total } & \multicolumn{2}{|c|}{ Cases $(n=426)$} & \multicolumn{2}{|c|}{ Controls $(n=614)$} \\
\hline & No. & $\begin{array}{l}\text { rcentage } \\
(\%)\end{array}$ & No. & $\begin{array}{c}\text { Percentage } \\
(\%)\end{array}$ \\
\hline Age (mean \pm s.D.) & \multicolumn{2}{|c|}{$29.4 \pm 6.2$} & \multicolumn{2}{|c|}{$35.2 \pm 5.8$} \\
\hline Tumor type & & & & \\
\hline Seminoma & 251 & 58.9 & - & - \\
\hline Nonseminoma & 175 & 41.1 & - & - \\
\hline \multicolumn{5}{|l|}{ Sperm count } \\
\hline $\begin{array}{l}\geq 40 \text { million/ } \\
\text { ejaculate }\end{array}$ & 219 & 51.4 & 414 & 67.4 \\
\hline $\begin{array}{l}<40 \text { million/ } \\
\text { ejaculate }\end{array}$ & 207 & 48.6 & 200 & 32.6 \\
\hline
\end{tabular}


Reagents and conditions for the PCR were $14.3 \mu \mathrm{l}$ $\mathrm{H}_{2} \mathrm{O}, 2.5 \mu \mathrm{l} 10 \times$ Gold Buffer, $1.5 \mu \mathrm{l} 25 \mathrm{mM} \mathrm{MgCl} \mathrm{Mg}_{2}$ solution (from Applied Biosystems, Branchburg, NJ, USA), $2.5 \mu \mathrm{l}$ dNTPs $(2 \mathrm{mM}$; from Amersham Biosciences), $1 \mu \mathrm{l}$ each primer $(10 \mu \mathrm{M}$; from SigmaAldrich), $0.2 \mu \mathrm{l} 5 \mathrm{U} / \mu \mathrm{l}$ AmpliTaq Gold (from Applied Biosystems), and $2 \mu \mathrm{l}$ template $(100 \mathrm{ng} / \mu \mathrm{l})$. The PCR program on a thermal cycler (GeneAMP PCR System 2700, Applied Biosystems, Monza, Italy) was first-step denaturation at $94{ }^{\circ} \mathrm{C}$ for $10 \mathrm{~min}$, followed by 37 cycles of $94{ }^{\circ} \mathrm{C}$ for $60 \mathrm{~s}, 58{ }^{\circ} \mathrm{C}$ for $60 \mathrm{~s}, 72{ }^{\circ} \mathrm{C}$ for $60 \mathrm{~s}$, and a final extension step of $4 \mathrm{~min}$ at $72{ }^{\circ} \mathrm{C}$.

\section{Statistical analysis}

Test for Hardy-Weinberg equilibrium (HWE) was performed with the use of the $\chi^{2}$ goodness-of-fit test. The extent of linkage disequilibrium (LD) among SNPs was quantified using Lewontin's $D^{\prime}$ value and the correlation coefficient $r^{2}$. Differences in allele and genotype distribution between cases and controls were tested with the use of Cochran-Armitage trend test. Odds ratios (ORs) and 95\% confidence interval (95\% CI) were estimated to assess the effect of each SNP on cancer risk using a logistic regression model. Allelic ORs and 95\% CIs were estimated on the basis of a multiplicative model. $P$ values were corrected to account for multiple comparisons using the false discovery rate Benjamini-Hochberg method. Twosided raw and adjusted $P$ values are reported, and adjusted $P<0.05$ was considered to indicate statistical significance. Statistical analyses were conducted using SAS version 9.2 (SAS Institute, Inc., Cary, NC, USA).

\section{Results}

We studied 426 TGCT cases (251 classic seminoma and 175 nonseminoma) and 614 controls, and both groups were considered as having a normal spermatogenesis when total sperm count was $\geq 40$ million/ ejaculate (Table 1). Genotyping was performed for two SNPs in the KITLG gene, rs995030 and rs4471514. The two markers were in strong LD $\left(D^{\prime}>0.95\right.$ and $\left.r^{2}>0.90\right)$ and in HWE both in controls and in cases.

We observed association of TGCT with both markers (corrected $P_{\text {trend }}=1.06 \times 10^{-9}$ and $5.48 \times$ $10^{-10}$ for $\mathrm{rs} 995030$ and $\mathrm{rs} 4471514$ respectively; Table 2). TGCT risk was increased more than twofold per copy of the major $\mathrm{G}$ allele and A allele in KITLG rs995030 and $\mathrm{rs} 4471514(\mathrm{OR}=2.38,95 \% \mathrm{CI}=$ $1.81-3.12 ; \mathrm{OR}=2.43,95 \% \mathrm{CI}=1.86-3.17$ respectively). Homozygotes for the risk allele had a sevenfold increased risk of TGCT $(\mathrm{OR}=7.04,95 \% \mathrm{CI}=2.10$

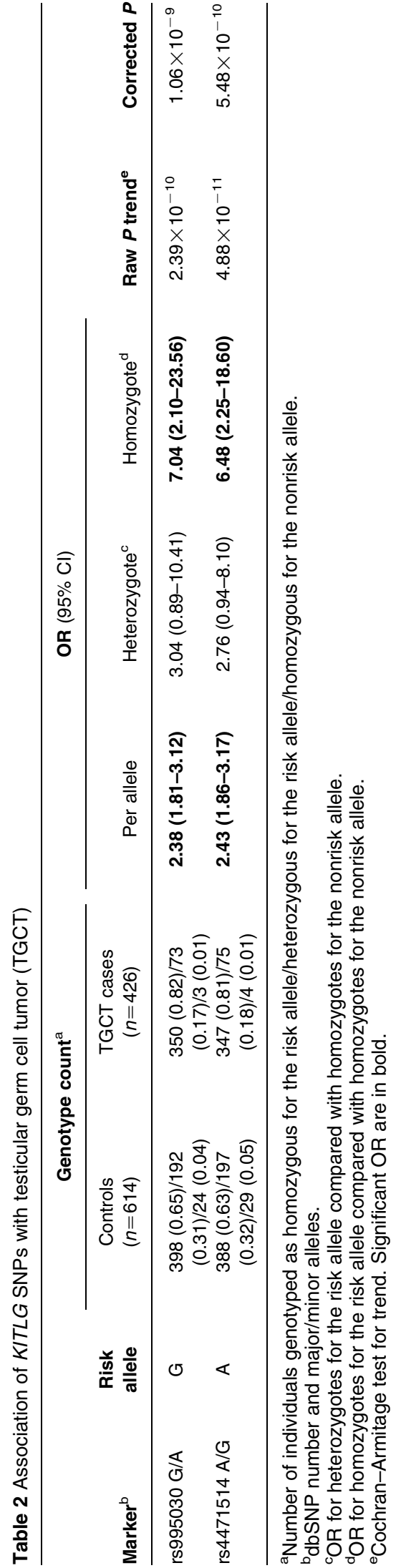


23.56; $\mathrm{OR}=6.48,95 \% \mathrm{CI}=2.25-18.60$, for $\mathrm{rs} 995030$ and rs4471514 respectively) compared with homozygotes for the nonrisk minor allele. Interestingly, KITLG markers were strongly associated with seminoma and weakly with nonseminoma (Table 3): seminoma risk was increased more than threefold per copy of the major $G$ allele and $A$ allele in KITLG rs995030 and rs4471514 (OR $=3.14,95 \%$ $\mathrm{CI}=2.18-4.54 ; \quad \mathrm{OR}=3.20, \quad 95 \% \quad \mathrm{CI}=2.24-4.58$ respectively), and homozygotes for the risk allele had a extremely high increased risk of seminoma $(\mathrm{OR}=13.01,95 \% \mathrm{CI}=1.75-96.71 ; \mathrm{OR}=16.00,95 \%$ $\mathrm{CI}=2.16-118.24$, for $\mathrm{rs} 995030$ and rs4471514 respectively) compared with homozygotes for the nonrisk minor allele. Nonseminoma risk was increased less than twofold per copy of the major $\mathrm{G}$ allele and $\mathrm{A}$ allele in $K I T L G$ rs 995030 and $\mathrm{rs} 4471514(\mathrm{OR}=1.73,95 \% \mathrm{CI}=$ $1.22-2.46 ; \mathrm{OR}=1.78,95 \% \mathrm{CI}=1.26-2.50$ respectively), and only a trend for significant OR for homozygotes for the risk allele was observed.

KITLG markers were not associated with spermatogenic function. In fact, both in controls and in TGCT cases, allele and genotype distribution were not different between subjects with normal ( $\geq 40$ million/ ejaculate) and low sperm count $(<40$ million/ ejaculate; Table 4), and this behavior was maintained in seminoma/nonseminoma cases. More detailed analysis of genotype distribution with respect to the severity of spermatogenic impairment (azoospermia, severe oligozoospermia, moderate oligozoospermia, and normozoospermia) failed to find association between KITLG markers and sperm count, both in controls and in TGCT cases. Furthermore, the mean sperm number was not different among the different genotypes and alleles (data not shown). Confirming the lack of association between KITLG markers and spermatogenic function, the increased risk per copy of the major alleles in KITLG rs995030 and rs4471514 was similar in TGCT cases with low sperm count compared with controls with low sperm count $(\mathrm{OR}=2.18,95 \%$ $\mathrm{CI}=1.53-3.11 ; \mathrm{OR}=2.16,95 \% \mathrm{CI}=1.53-3.05$, for rs995030 and rs4471514 respectively) and in TGCT cases with normal sperm count compared with controls with normal sperm count $(\mathrm{OR}=2.62,95 \%$ $\mathrm{CI}=1.71-4.01 ; \mathrm{OR}=2.75,95 \% \mathrm{CI}=1.80-4.20$, for rs995030 and rs4471514 respectively; Table 5).

\section{Discussion}

Taken together, these data showed association of KITLG markers with TGCT, especially the seminoma subtype, independently from the spermatogenic function. By using one marker previously identified 
in US cases (rs4471514; Kanetsky et al. 2009) and one marker previously identified in UK cases (rs995030; Rapley et al. 2009), we therefore replicated in Italians a similar increased risk of disease per major allele (2.5-fold). We also confirmed the risk of TGCT only for homozygotes for the risk allele (sevenfold increase) and not for the heterozygotes. However, association was found only for seminoma and not for nonseminoma. Different hypotheses might explain this different result, including ethnic differences, histological classification, or different number of cases (although the numbers were similar: 175 nonseminoma in our series, 180 and 141 in the discovery and replication phase of the US study, and 241 and 171 in the discovery and replication phase of the UK study). Studies dealing with genetic predisposition of TGCT frequently found differences between seminoma and nonseminoma. The $\mathrm{gr} / \mathrm{gr}$ deletion of the $\mathrm{Y}$ chromosome is strongly associated with seminoma than with nonseminoma (Nathanson et al. 2005), longer CAG repeats on the androgen receptor gene are mainly associated with nonseminoma (Giwercman et al. 2004), and we also found higher association of FSH receptor (FSHR) polymorphisms only with nonseminoma (Ferlin et al. 2008), and on the contrary stronger association of hydroxysteroid (17-beta) dehydrogenase 4 (HSD17B4) markers with seminoma (Ferlin et al. 2010). Therefore, it might also be possible that the two classes of TGCTs might have different pathogenesis. Indeed, somatic KIT alterations are far more frequent in seminoma than in nonseminoma (Forbes et al. 2008).

Another possibility is related to the presence of possible confounding risk factors. In fact, both GWAS included subjects with familial history of TGCT and personal history of cryptorchidism (Kanetsky et al. 2009, Rapley et al. 2009), which represent to date the most important clinical risk factor for TGCT with a relative risk of 4.8 (Dieckmann \& Pichlmeier 2004). On the contrary, they did not consider another important risk factor for TGCT, infertility, or low sperm count. Nevertheless, we did not observe association of KITLG markers with spermatogenic function, both in controls and in TGCT cases. Therefore, variations in KITLG seem to represent an independent and strong specific risk factor for TGCT.

KITLG-KIT pathway involvement in TGCTs is supported by numerous evidences: high expression of KIT, somatic activating mutations, and genomic amplification of KIT are frequently seen in TGCTs (especially seminomas; Izquierdo et al. 1995, Strohmeyer et al. 1995, Bokemeyer et al. 1996, Rapley et al. 2004, McIntyre et al. 2005, Goddard et al. 2007); germline deletions of Kitlg increase susceptibility to

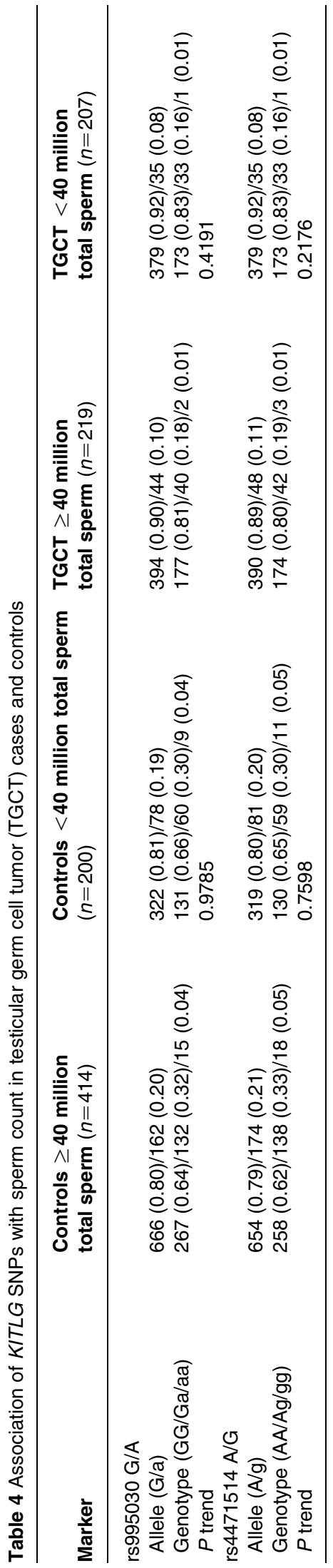




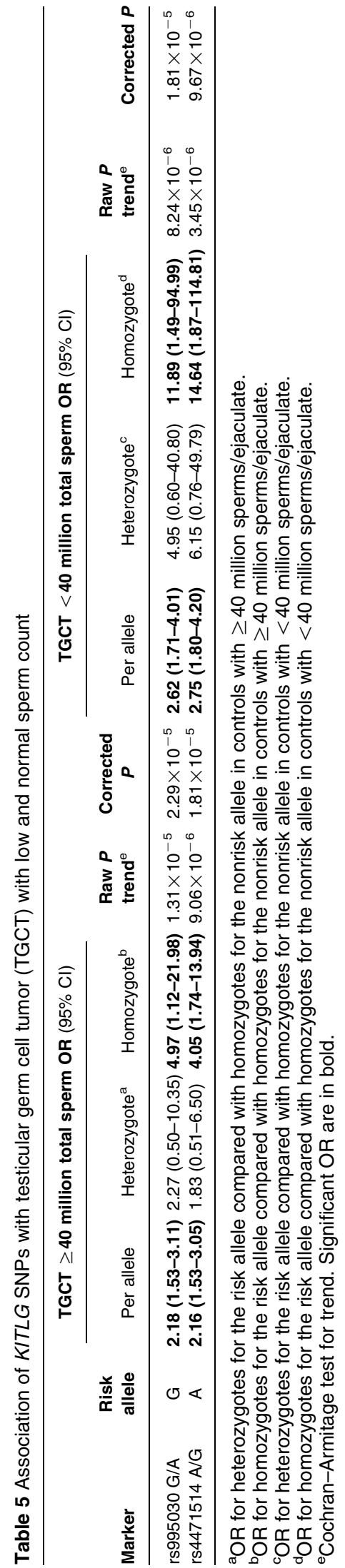

TGCTs in mice (Heaney et al. 2008); other than $K I T L G$, two of the loci identified by GWAS (SPRY4 and BAK1; Kanetsky et al. 2009, Rapley et al. 2009) are involved in the KITLG-KIT pathway. The KITLG-KIT system is critical for the correct development of PGCs (Runyan et al. 2006, Boldajipour \& Raz 2007), the cells from which TGCT is believed to arise. Delayed differentiation of PGCs has been associated with the development of TGCT in mice (Heaney et al. 2008) and humans (Rajpert-De Meyts \& Hoei-Hansen 2007). Furthermore, germline homozygous-null mutations of either Kit or Kitlg lead to infertility in mice as a result of a failure of PGC development (Heaney et al. 2008). In spite of this postulated role of KITLG-KIT signaling pathway in male fertility (Blume-Jensen et al. 2000, Mahakali Zama et al. 2005, Runyan et al. 2006) and epidemiological data suggesting an association between TGCT and male infertility (Richiardi \& Akre 2005), our data do not support a common genetic link between these two conditions, at least regarding variations in KITLG gene. Only one preliminary small study analyzing different KIT and KITLG markers in infertile males implicated this system in spermatogenic disruption also in humans (Galan et al. 2006). However, in accordance to our findings, that study failed to find association between KITLG rs995030 and male infertility. Larger studies are probably needed to correctly assess the possible association between KITLG markers and spermatogenesis, taking into account that, although epidemiological data suggest that male infertility confers a significantly increased risk of TGCT (standardized incidence ratio 2.8, 95\% CI =1.5-4.8; Walsh et al. 2009), the prevalence of TGCT in men with infertility or azoooligozoospermia is low (0.3\%; Jacobsen et al. 2000, Walsh et al. 2009). Anyway, the phenotype 'TC' for which association with KITLG variants was found is definite and specific (germ cell tumor, especially the seminoma subtype), whereas male infertility is clearly a multifactor entity. Therefore, it is conceivable that a putative involvement of KITLG-KIT pathway disruption could be observed only in well-defined subtypes of 'idiopathic' spermatogenic impairment. While we tried to remove all other potential causes, male infertility is a heterogeneous condition and any effect of risk alleles might be subtle and difficult to detect because the risk alleles are at high frequency. Therefore, the power to detect a difference was limited and a much larger study is needed to conclude on a possible association between KITLG markers and male infertility.

In conclusion, our study not only further supports that KITLG variants are involved in TGCT development but also highlights that they represent an 
independent and strong specific risk factor for TGCT, independently from spermatogenic function. Therefore, a shared genetic cause and a common pathogenetic link between TGCT development and impairment of spermatogenesis still remain to be elucidated.

\section{Declaration of interest}

The authors declare that there is no conflict of interest that could be perceived as prejudicing the impartiality of the research reported.

\section{Funding}

This work was supported by the Italian Ministry of University and Research (MIUR; grant number 2007TKYYJR). The funder had no role in the study design, data collection and analysis, decision to publish, or preparation of the manuscript.

\section{Author contribution statement}

A Ferlin and C Foresta participated in study design. A Ferlin, D Pizzol, U Carraro, and C Foresta enrolled patients. A C Frigo undertook statistical analysis. M Pengo made molecular analyses. A Ferlin, M Pengo, and A C Frigo contributed to data collection and generation of tables and figures. A Ferlin had full access to all of the data in the study and takes responsibility for the integrity of the data and the accuracy of the data analysis. All authors had full access to the original data, reviewed the data analyses, contributed to data interpretation and to the writing of the report, made final decisions on all parts of the report, and approved the final version of the submitted report.

\section{References}

Blume-Jensen P, Jiang G, Hyman R, Lee KF, O'Gorman S \& Hunter T $2000 \mathrm{Kit} /$ stem cell factor receptor-induced activation of phosphatidylinositol $3^{\prime}$-kinase is essential for male fertility. Nature Genetics 24 157-162. (doi:10.1038/72814)

Bokemeyer C, Kuczyk MA, Dunn T, Serth J, Hartmann K, Jonasson J, Pietsch T, Jonas U \& Schmoll HJ 1996 Expression of stem-cell factor and its receptor c-kit protein in normal testicular tissue and malignant germcell tumours. Journal of Cancer Research and Clinical Oncology 122 301-306. (doi:10.1007/BF01261407)

Boldajipour B \& Raz E 2007 What is left behind - quality control in germ cell migration. Science's STKE : Signal Transduction Knowledge Environment 383 pe16. (doi:10. 1126/stke.3832007pe16)

Chanock S 2009 High marks for GWAS. Nature Genetics 41 765-766. (doi:10.1038/ng0709-765)

Crockford GP, Linger R, Hockley S, Dudakia D, Johnson L, Huddart R, Tucker K, Friedlander M, Phillips KA, Hogg D et al. 2006 Genome-wide linkage screen for testicular germ cell tumour susceptibility loci. Human Molecular Genetics 15 443-451. (doi:10.1093/hmg/ddi459)
Czene K, Lichtenstein P \& Hemminki K 2002 Environmental and heritable causes of cancer among 9.6 million individuals in the Swedish Family-Cancer Database. International Journal of Cancer 99 260-266. (doi:10. 1002/ijc.10332)

Dieckmann KP \& Pichlmeier U 2004 Clinical epidemiology of testicular germ cell tumors. World Journal of Urology 22 2-14. (doi:10.1007/s00345-004-0398-8)

Dong C \& Hemminki K 2001 Modification of cancer risks in offspring by sibling and parental cancers from 2112616 nuclear families. International Journal of Cancer $\mathbf{9 2}$ 144-150. (doi:10.1002/1097-0215(200102)9999:9999< ::AID-IJC1147> 3.0.CO;2-C)

Ferlin A, Tessari A, Ganz F, Marchina E, Barlati S, Garolla A, Engl B \& Foresta C 2005 Association of partial AZFc region deletions with spermatogenic impairment and male infertility. Journal of Medical Genetics 42 209-213. (doi:10.1136/ jmg.2004.025833)

Ferlin A, Arredi B, Speltra E, Cazzadore C, Selice R, Garolla A, Lenzi A \& Foresta C 2007 Molecular and clinical characterization of $\mathrm{Y}$ chromosome microdeletions in infertile men: a 10-year experience in Italy. Journal of Clinical Endocrinology and Metabolism 92 762-770. (doi:10.1210/jc.2006-1981)

Ferlin A, Pengo M, Selice R, Salmaso L, Garolla A \& Foresta C 2008 Analysis of single nucleotide polymorphisms of FSH receptor gene suggests association with testicular cancer susceptibility. Endocrine-Related Cancer 15 429-437. (doi:10.1677/ERC-07-0257)

Ferlin A, Ganz F, Pengo M, Selice R, Frigo AC \& Foresta C 2010 Association of testicular germ cell tumor with polymorphisms in estrogen receptor and steroid metabolism genes. Endocrine-Related Cancer 17 17-25. (doi:10.1677/ERC-09-0176)

Forbes SA, Bhamra G, Bamford S, Dawson E, Kok C, Clements J, Menzies A, Teague JW, Futreal PA \& Stratton MR 2008 The catalogue of somatic mutations in cancer (COSMIC). Current Protocols in Human Genetics. (doi:10.1002/0471142905.hg1011S57)

Galan JJ, De Felici M, Buch B, Rivero MC, Segura A, Royo JL, Cruz N, Real LM \& Ruiz A 2006 Association of genetic markers within the KIT and KITLG genes with human male infertility. Human Reproduction 21 3185-3192. (doi:10. 1093/humrep/del313)

Giwercman A, Lundin KB, Eberhard J, Ståhl O, Cwikiel M, Cavallin-Ståhl E \& Giwercman YL 2004 Linkage between androgen receptor gene CAG trinucleotide repeat length and testicular germ cell cancer histological type and clinical stage. European Journal of Cancer $\mathbf{4 0}$ 2152-2158. (doi:10.1016/j.ejca.2004.06.004)

Goddard NC, McIntyre A, Summersgill B, Gilbert D, Kitazawa S \& Shipley J 2007 KIT and RAS signalling pathways in testicular germ cell tumours: new data and a review of the literature. International Journal of Andrology 30 337-348. (doi:10.1111/j.1365-2605.2007. 00769.x) 
Heaney JD, Lam MY, Michelson MV \& Nadeau JH 2008 Loss of the transmembrane but not the soluble kit ligand isoform increases testicular germ cell tumor susceptibility in mice. Cancer Research 68 5193-5197. (doi:10.1158/ 0008-5472.CAN-08-0779)

Hemminki K \& Li X 2004 Familial risk in testicular cancer as a clue to a heritable and environmental aetiology. British Journal of Cancer 90 1765-1770. (doi:10.1038/sj.bjc. 6601714)

Horwich A, Shipley J \& Huddart R 2006 Testicular germ-cell cancer. Lancet 367 754-765. (doi:10.1016/S01406736(06)68305-0)

Izquierdo MA, Van der Valk P, Van Ark-Otte J, Rubio G, Germa-Lluch JR, Ueda R, Scheper RJ, Takahashi T \& Giaccone G 1995 Differential expression of the c-kit proto-oncogene in germ cell tumours. Journal of Pathology 177 253-258. (doi:10.1002/path.1711770307)

Jacobsen R, Bostofte E, Engholm G, Hansen J, Olsen JH, Skakkebaek NE \& Moller H 2000 Risk of testicular cancer in men with abnormal semen characteristics: cohort study. BMJ 321 789-792. (doi:10.1136/bmj.321.7264.789)

Kanetsky PA, Mitra N, Vardhanabhuti S, Li M, Vaughn DJ, Letrero R, Ciosek SL, Doody DR, Smith LM, Weaver J et al. 2009 Common variation in KITLG and at 5q31.3 predisposes to testicular germ cell cancer. Nature Genetics 41 811-815. (doi:10.1038/ng.393)

Kanetsky PA, Mitra N, Vardhanabhuti S, Vaughn DJ, Li M, Ciosek SL, Letrero R, D'Andrea K, Vaddi M, Doody DR et al. 2011 A second independent locus within DMRT1 is associated with testicular germ cell tumor susceptibility. Human Molecular Genetics 20 3109-3117. (doi:10.1093/ hmg/ddr207)

Mahakali Zama A, Hudson FP III \& Bedell MA 2005 Analysis of hypomorphic KitlSl mutants suggests different requirements for KITL in proliferation and migration of mouse primordial germ cells. Biology of Reproduction 73 639-647. (doi:10.1095/biolreprod.105.042846)

McIntyre A, Summersgill B, Grygalewicz B, Gillis AJ, Stoop J, van Gurp RJ, Dennis N, Fisher C, Huddart R, Cooper C et al. 2005 Amplification and overexpression of the KIT gene is associated with progression in the seminoma subtype of testicular germ cell tumors of adolescents and adults. Cancer Research 65 8085-8089. (doi:10.1158/0008-5472. CAN-05-0471)

Nathanson KL, Kanetsky PA, Hawes R, Vaughn DJ, Letrero R, Tucker K, Friedlander M, Phillips KA, Hogg D, Jewett MA et al. 2005 The Y deletion gr/gr and susceptibility to testicular germ cell tumor. American Journal of Human Genetics 77 1034-1043. (doi:10.1086/498455)

Rajpert-De Meyts E 2006 Developmental model for the pathogenesis of testicular carcinoma in situ: genetic and environmental aspects. Human Reproduction Update 12 303-323. (doi:10.1093/humupd/dmk006)

Rajpert-De Meyts E \& Hoei-Hansen CE 2007 From gonocytes to testicular cancer: the role of impaired gonadal development. Annals of the New York Academy of Sciences 1120 168-180. (doi:10.1196/annals.1411.013)
Rapley EA, Hockley S, Warren W, Johnson L, Huddart R, Crockford G, Forman D, Leahy MG, Oliver DT, Tucker K et al. 2004 Somatic mutations of KIT in familial testicular germ cell tumours. British Journal of Cancer 90 2397-2401.

Rapley EA, Turnbull C, Al Olama AA, Dermitzakis ET, Linger R, Huddart RA, Renwick A, Hughes D, Hines S, Seal S et al. 2009 A genome-wide association study of testicular germ cell tumor. Nature Genetics 41 807-810. (doi:10.1038/ng.394)

Richiardi L \& Akre O 2005 Fertility among brothers of patients with testicular cancer. Cancer Epidemiology, Biomarkers \& Prevention 14 2557-2562. (doi:10.1158/ 1055-9965.EPI-05-0409)

Runyan C, Schaible K, Molyneaux K, Wang Z, Levin L \& Wylie C 2006 Steel factor controls midline cell death of primordial germ cells and is essential for their normal proliferation and migration. Development 133 4861-4869. (doi:10.1242/dev.02688)

Skakkebaek NE, Rajpert-De Meyts E \& Main KM 2001 Testicular dysgenesis syndrome: an increasingly common developmental disorder with environmental aspects.

Human Reproduction 16 972-978. (doi:10.1093/humrep/ 16.5.972)

Stouffs K, Lissens W, Tournaye H \& Haentjens P 2011 What about gr/gr deletions and male infertility? Systematic review and meta-analysis Human Reproduction Update 17 197-209. (doi:10.1093/humupd/dmq046)

Strohmeyer T, Reese D, Press M, Ackermann R, Hartmann M \& Slamon D 1995 Expression of the c-kit proto-oncogene and its ligand stem cell factor (SCF) in normal and malignant human testicular tissue. Journal of Urology 153 511-515. (doi:10.1097/00005392-199502000-00073)

Swerdlow AJ, De Stavola BL, Swanwick MA \& Maconochie NE 1997 Risks of breast and testicular cancers in young adult twins in England and Wales: evidence on prenatal and genetic aetiology. Lancet 350 1723-1728. (doi:10.1016/S0140-6736(97)05526-8)

Turnbull C, Rapley EA, Seal S, Pernet D, Renwick A, Hughes D, Ricketts M, Linger R, Nsengimana J, Deloukas $\mathrm{P}$ et al. 2010 Variants near DMRT1, TERT and ATF7IP are associated with testicular germ cell cancer. Nature Genetics 42 604-607. (doi:10.1038/ng.607)

Walsh TJ, Croughan MS, Schembri M, Chan JM \& Turek PJ 2009 Increased risk of testicular germ cell cancer among infertile men. Archives of Internal Medicine 169 351-356. (doi:10.1001/archinternmed.2008.562)

World Health Organization 1999 WHO Laboratory Manual for the Examination of Human Semen and Sperm-Cervical Mucus Interaction. Cambridge, UK: Cambridge University Press.

Received in final form 19 December 2011 Accepted 22 December 2011 Made available online as an Accepted Preprint 22 December 2011 